\title{
Single Mother's Adverse and Traumatic Experiences and Post-Traumatic Stress Symptoms
}

\author{
Joan A. Samuels-Dennis \& Marilyn Ford-Gilboe \&
}

Susan Ray

\begin{abstract}
A random sample of 247 Canadian single mothers currently receiving social assistance participated in a study designed to: a) provide a comprehensive description of mother's lifetime exposure to 11 adversities, four psychological traumas, and eight assaultive traumas; b) examine the association between exposure to childhood and adulthood adversities and traumas, and mother's current post-traumatic stress symptom. Of those surveyed, $31 \%$ met the criteria for a probable PTSD diagnosis. Between $78 \%$ and $80 \%$ reported 1 or more lifetime adversity, psychological trauma, and assaultive trauma. Rates of adversities were similar to the general female population. However, rates of psychological and assaultive trauma were six to ten times greater than the general female population. Results show that level of exposure to psychological and assaultive traumas, but not adversity, differentially impacted both the patterning and severity of mothers' current PTSD symptoms. Psychological trauma exposure was the only event type that differentiated the mean scores for the re-experiencing, avoidance/numbing, and hyper-arousal symptom clusters. While exposure to assaultive trauma differentiates mean
\end{abstract}

This research was supported by a doctoral fellowship from the Ontario Women's Health Council (OWHC)/Canadian Institute of Health Research (CIHR) awarded to Joan Samuels-Dennis.

\footnotetext{
J. A. Samuels-Dennis (*)

Faculty of Health, School of Nursing, York University, 4700 Keele Street,

Toronto, ON M3J 1P3, Canada

e-mail: jsdennis@yorku.ca

M. Ford-Gilboe: S. Ray

Faculty of Health Science, School of Nursing,

University of Western Ontario,

London, Ontario, Canada
}

scores primarily for the avoidance/numbing symptoms cluster. Implications for health promotion initiatives across health and social service sectors are discussed.

Keywords Post-traumatic stress symptoms - Single mothers. Psychological and assaultive trauma . Social assistance

Although the mental health of single mothers has been studied extensively, researchers across disciplines have focused primarily on depression as a central mental health outcome contextualized by stressful life events, employment status, and poverty (see Avison et al. 2007; Brown and Moran 1997; Davies et al. 1997). Surprisingly, traumatic experiences and post-traumatic stress disorder (PTSD) have received little attention. Across a range of general population studies conducted in Canada and the United States (U.S.), it has been demonstrated that between $3 \%$ and $10 \%$ of the general female population will experience PTSD over their lifetime (Breslau et al. 1998; Kessler et al. 1995; Stein et al. 1997). Although a modest prevalence rate, current literature also suggests that this debilitating mental health problem is not equally distributed among women. That is, a critical examination of PTSD prevalence rates among sub-groups of women reveals that that some women experience more advantage or disadvantage in terms of their risk for lifetime PTSD. Married mothers appear to be the most advantaged with $8 \%$ experiencing lifetime PTSD when compared their never married $(17 \%)$ and separated/divorced counterpart (23\%) (Afifi et al. 2006; Bassuk et al. 1998; Tolman and Rosen 2001). Even in light of these alarming statistics, the income-assisted single mother appears to be the most disadvantaged with approximately $30 \%$ experiencing PTSD over their lifetime. 
According to the Diagnostic and Statistical Manual of Mental Disorders (American Psychiatric Association 2000), PTSD is caused by exposure to a traumatic event (Criterion A) in which both of the following are present:

1. The event involved actual or threatened death or serious injury, or a threat to the physical integrity of others:

2. The individual's response involved intense fear, helplessness, or horror.

While this conceptualization possesses an inherent gender-bias, it never the less helps us identify violence against women, in particular, intentional assaultive violence, as the event type most likely to precipitate PTSD among women. Breslau et al. (1999) incorporated Criterion $A$ in a gender-sensitive analysis to investigate the reasons for the disproportionate rate of PTSD (2:1) among women when compared to men. They compared the conditional risk of PTSD in females versus males across traumatic events to determine whether the excess risk in females was associated with the nature of the event. Their findings revealed that the overall sex difference in the conditional risk of PTSD $(35 \pm 7 \%$ in females vs. $6 \pm 0 \%$ in males) was due primarily to females' greater risk of PTSD following exposure to assaultive violence. Though not systematically investigated, this and other studies suggest that the higher rates of PTSD found among income-assisted single mothers compared to the general female population is in-part explained by women's trauma histories. Income-assisted mothers compared to the general female population report substantially higher rates of physical abuse, sexual abuse, physical assault by strangers, physical partner violence, and sexual partner violence (Breslau et al. 1998; Kessler et al. 1995; Lown et al. 2006; Lutenbacher 2000; Schumm et al. 2006; Tjaden and Thoennes 2000; Tolman and Rosen 2001).

While the vulnerability to assaultive violence hypothesis (Breslau et al. 1999) offers some important considerations for research and clinical practice, it remains problematic that psychological violence is excluded from such analyses. We have argued elsewhere (Samuels-Dennis et al. 2010b) that although assaultive and psychological traumas frequently occur together, they remain qualitatively distinct. Assaultive traumas represent discrete and/or enduring offensive physical and sexual encounters that precipitate a state of intense fear, anxiety and apprehension, loss of control, and powerlessness in the victim (Herman 1997). Alternatively, psychological traumas refer to enduring and personally uncontrollable life circumstances characterized by fear, intimidation, and manipulation (Goodman et al. 2003; Goodman et al. 1991; Herman 1997). Each is used as a means of acquiring control and together they are detrimental to the human psyche. The relevance of psychological violence is highlighted by studies examining the link between intimate partner violence (IPV) and PTSD (Coker et al. 2002; Pico-Alfonso 2005; Smith et al. 2002). These studies suggest that psychological violence, compared to physical or sexual violence, may have an equal, if not greater, effect on the development and persistence of PTSD. Perhaps as Breslau et al. found, psychological and assaultive traumas will affect each cluster of PTSD symptom spectrum (re-experiencing, avoidance/numbing, and hyperarousal) differently. This is an important gap in knowledge that if addressed will inform our understanding of how specific trauma types impact PTSD symptomology among women and, in turn, assist with the development of eventspecific interventions.

Beyond, the absence of psychological violence in the trauma-PTSD literature, the conceptualization of Criterion $A$ has been recently challenged by scholars who question the assumption that the focal trauma or precipitating event must reach the level of severity and intensity outlined by the DSM-IV-TR. Lloyd and Turner (2003) found that a more diverse array of events which vary naturally in their intensity and severity contribute to PTSD symptom levels than had been previously assumed. These events include: 1) major life events, such as parental divorce or failing a grade in school; 2) life traumas involving force or violence, such as rape or physical abuse; 3) witnessing events, such as seeing someone killed or attacked; 4) traumatic news events, including hearing about someone's death; and, 5) death events, such as experiencing the death of a family member or friend. This body of work supports the notion that events traditionally viewed as adversities, have a part to play in the development of PTSD. It also calls for the explicit recognition that all experiences matter and that the complex interaction between traumas of different forms (i.e., adversities, psychological and assaultive traumas) is the central determinant of women's current mental health.

Trauma exposure attends only partially to the complex story associated with women's life experiences and the multiple forms of oppression they face over their life. However, the presence or absence of violence is an important component in the web of early- and later-life challenges that income-assisted mothers face, and, it is necessary for developing population specific interventions directed at preventing trauma and promoting mental wellbeing. We are aware of only three studies (Salomon et al. 2004; Schumm et al. 2006; Tolman and Rosen 2001) that address the link between trauma and PTSD among this population. All three were conducted in the U.S., and none examine the relative importance of the nature of events to women's current PTSD symptom levels. If women's greater risk for PTSD is indeed explained by a vulnerability to particular types of traumas, it is important that researchers provide a comprehensive assessment of mothers' adverse 
and traumatic experiences while also accounting for the potential path through which symptoms develop and persist.

In this report, a complete history of 23 traumatic events was gathered from 247 income assisted single mothers living in Ontario, Canada. Additionally, we assessed the connection between event categories (adversity, psychological trauma, and assaultive trauma) and the severity and patterning of mothers PTSD symptoms.

Specifically, we address the following research questions: (1) what are the lifetime rates of exposure to adversities, psychological trauma, and assaultive traumas among income assisted single mothers? (2) Is lifetime exposure to multiple forms of adversities, psychological traumas, and assaultive traumas associated with PTSD symptom severity? (3) Does lifetime exposure to multiple forms of adversities, psychological traumas, and assaultive trauma differentially affect mothers' PTSD symptomology?

\section{Method}

Design

This analysis is part of a larger cross-sectional study aimed at partially testing the validity of the intersectionality model of trauma and post-traumatic stress disorder. The larger study (Samuels-Dennis et al. 2010a) investigated the process through which cumulative trauma affects PTSD symptoms among a sample of 247 single mothers receiving social assistance from a large metropolitan city in Ontario, Canada.

\section{Sample}

A random sample of 247 single mothers was recruited from the active caseload of the provincial social assistance program. Ontario's social assistance programs provides temporary financial assistance to residents of Ontario who are in financial need by providing money to assist with housing and other basic needs and by supporting individuals with acquiring and maintaining employment (Ontario Ministry of Community and Social Services 2010). In April of 2010, 251,120 individuals or family units were actively receiving social assistance. Sole-support parents receiving financial assistance accounted for 75,172 of the total number of social assistance cases with $95 \%$ of those being single mothers (Ontario Ministry of Community and Social Services 2010).

Figure 1 outlines the sample recruitment process: a modified version of (Dillman 1991) total design method. After receiving ethical approval from the Institutional Review Board at the study site, a total of 2,400 single mothers randomly selected from the active caseload of the social service agency were contacted by mail between January and February, 2008, to request their participation in the study. In total, 293 single mothers contacted the principal investigator by telephone, mail, or e-mail to
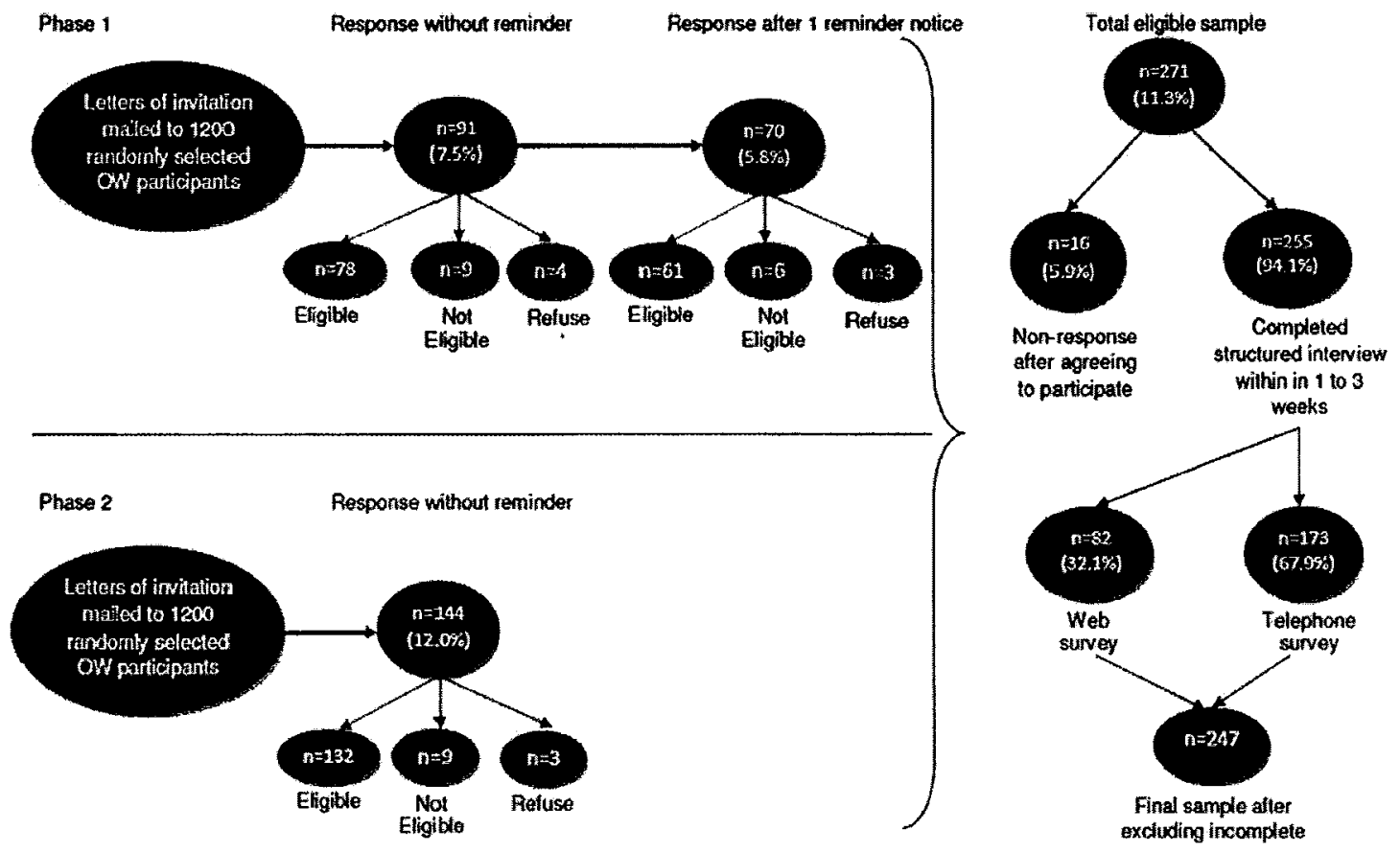

Fig. 1 Sample recruitment 
indicate their interest in taking part in the study, 10 of whom subsequently indicated that they were not interested in taking part. All participants were screened to ensure that they met the following eligibility criteria: 1) recipients of social assistance for at least 6 months; 2) currently living with a least one dependent child ( $<18$ years old); 3 ) not currently living with a spouse or common law partner; and 4) able to effective read or communicate in English. Of the 271 single mothers who met the eligibility criteria, 255 (95\%) completed a telephone $(n=173)$ or on-line $(n=82)$ survey. Six percent $(n=16)$ did not complete the survey because they were lost to follow up or were too busy. To maximize the response rate, as many as six follow-up phone calls were made to participants who did not complete the survey by the mutually agreed upon date and time. Eight surveys were excluded because they contained substantial missing data, resulting with a final sample of 247. No demographic differences were noted between women who completed the survey online versus by telephone. Thus, these two groups were analyzed together.

The extremely low response rate $(11.3 \%)$ diminishes our ability to generalize these findings to the wider population of income-assisted single mothers. However, compared to the approximately 20,000 single mothers currently receiving social assistance in the greater Toronto area (GTA), participants of this study were similar with respect to age, number of children, and employment status, but were more educated and less likely to be immigrants (Toronto Community and Neighbourhood Services 2004). A number of factors may have resulted in the low response rates. First, invitations were mailed just after Christmas, a busy time of year for most families. Second, the study letter of information which outlined the potential for a stress response post-participation may have deterred participation. Third, the inability of the social service agency to select participants who were fluent in English may have resulted in the selection of a sample that could not read or write English and thus ineligible participants. Fourth, the extent to which mothers' cultural background also affected their willingness to discuss the issues addressed by this study is not known. Finally, it remains unclear exactly how many single fathers received an invitation to participate in the study.

Table 1 provides an overview of the demographic characteristics of the sample. The average age of participants was 35.7 years ( $S D=9.5$, Range $18-61$ years). More than half $(56.1 \%)$ of the sample were single, never-married mothers while $42.4 \%$ were separated or divorced. Caucasians made up the largest proportion of the sample (37.7\%) followed by Blacks (28.5\%), and Hispanics (7.5\%). Almost $40 \%$ of the study participants reported completing high school, while just over $49 \%$ reported having some postsecondary education. Twenty-two percent of women were
Table 1 Sample characteristics

\begin{tabular}{|c|c|c|}
\hline \multirow[t]{2}{*}{ Characteristics } & \multicolumn{2}{|c|}{ Total sample $(\mathrm{N}=247)$} \\
\hline & $n(\%)$ & Mean (SD) \\
\hline Age $(n=245)$ & & $35.7(9.5)$ \\
\hline Number of children $(n=246)$ & & $1.8(1.04)$ \\
\hline \multicolumn{3}{|l|}{ Marital Status $(n=244)$} \\
\hline Single never married & $137(56.5)$ & \\
\hline Separated/Divorced & $103(42.2)$ & \\
\hline Widowed & $4(1.6)$ & \\
\hline \multicolumn{3}{|l|}{ Race/Ethnicity $(n=239)$} \\
\hline Native /Aboriginal & $12(5.0)$ & \\
\hline Black & $63(28.5)$ & \\
\hline Caucasian & $90(37.7)$ & \\
\hline East and Southeast Asian & $10(4.2)$ & \\
\hline Pacific Islander/Filipino & $1(0.4)$ & \\
\hline South Asian/East Indian & $16(6.7)$ & \\
\hline Hispanic/Latin American & $18(7.5)$ & \\
\hline Middle Eastern/Arab & $6(2.5)$ & \\
\hline Bi-racial & $18(7.5)$ & \\
\hline \multicolumn{3}{|l|}{ Education $(n=244)$} \\
\hline Less than high school & $29(11.9)$ & \\
\hline High school graduate & $95(38.9)$ & \\
\hline Some college/university & $47(19.3)$ & \\
\hline College/University graduate & $73(29.9)$ & \\
\hline \multicolumn{3}{|l|}{ Employment status $(n=246)$} \\
\hline Employed full-time & $15(6.1)$ & 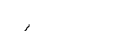 \\
\hline Employed part-time & $41(16.7)$ & \\
\hline Unemployed & $190(77.2)$ & \\
\hline \multicolumn{3}{|l|}{ Immigration status $(n=247)$} \\
\hline Born in Canada & $134(54.3)$ & \\
\hline Born outside Canada & $113(45.7)$ & \\
\hline
\end{tabular}

${ }^{8}$ Percentage shown are valid percentages

employed either part-time or full-time, but still receiving some social assistance. About half of the sample (45.7\%) reported that they immigrated to Canada. The average number of years since immigration was $16.0(S D=10)$.

\section{Data Collection Procedure}

After providing informed consent, women completed a structured interview designed to assess lifetime exposure to adversity and trauma, current symptoms of PTSD, use of health services, personal and social resources, and selected demographic characteristics. Women were given the choice of completing the survey on-line using Survey Monkey or by telephone with an interviewer who had been trained in conducting safe telephone interviews with potential survivors of trauma. Interviewers also used 
Survey Monkey as a data entry tool and completed the survey on-line as they interviewed participants in the study. Interviews lasted an average of 45 min (ranging from 30 to $120 \mathrm{~min}$ ) and those women who completed the interview received a $\$ 20.00$ voucher for a local store to compensate them for their time or other costs associated with participation.

\section{Measures}

Data were collected using established measures of trauma, adversities and PTSD symptoms as well as a demographic questionnaire to gather information about women's marital status, number of children, self-identified racial and ethnic background, immigrant status and country of origin, neighborhood of residence, level of education and work status.

\section{Traumas and Adversities}

Adversities, assaultive traumas, and psychological traumas were originally assessed using 33 items taken from three trauma inventories: 1) the Composite International Diagnostic Interview-PTSD module (14 items: World Health Organization 2004), 2) a measure of stress exposure (three items: Turner and Avison 2003), and, 3) the Betrayal Trauma Survey (six items: Goldberg and Freyd 2006). The selection of these 33 items was based on a comprehensive review of the literature on trauma and mental health as well as the relevance of these items to an urban sample of single mothers.

The rare occurrence of some events (i.e., war, peacekeeper, forced participation in the sex trade industry), the inability to theoretically differentiate between events (physical abuse and physical neglect), and a preliminary confirmatory factor analysis led to the selection of the 23 items use in this analysis (see also Samuels-Dennis et al. 2010a). The items include 11 adversities (i.e., becoming a refugee, life-threatening auto accident); four psychological traumas (i.e., childhood emotional abuse, psychological IPV); and eight assaultive traumas (i.e., childhood physical abuse, physical assault by a stranger). Participants were asked to indicate if they had ever experienced each event and, if so, the number of times the event occurred during childhood (before age 18) and adulthood (on or after age 18). Responses were coded 0 (no exposure) or 1 (at least one occurrence) for each developmental stage. Exposure scores were calculated using the following procedure: First, adversity, psychological trauma, and assaultive trauma exposure scores were calculated for childhood and adulthood. Second, childhood and adulthood exposure scores were added together for the adversity (Range 0 to 9), psychological trauma (Range 0 to 9), and assaultive trauma (Range 0 to 12) categories. Third, for each category of event we created levels of multiple exposure where be $0=$ no lifetime exposure to any event within that category, $1=$ exposure to 1 or 2 unique events within that category, and $3=$ exposure to 3 or more unique events within that category.

\section{PTSD Symptoms}

Severity of PTSD symptoms was assessed using the Davidson Trauma Scale (DTS: Davidson 1996; Davidson et al. 2002), a 17-item scale which measures the frequency and severity of PTSD symptoms across three domains: 1) Intrusion-persistent re-experiencing of a traumatic event, 2) avoidance/numbing-avoidance of stimuli associated with the trauma and numbing of general responsiveness, and, 3) hyper-arousal-persistent heightened arousal or hypersensitivity. After defining a traumatic event and providing examples, participants were asked the following question: "In your lifetime, have you experienced a traumatic event?" Participants who responded positively to this question were asked to rank, on a 5-point likert scale, the frequency $(0=$ not at all to $4=$ every day) and severity ( $0=$ not at all distressing to $4=$ extremely distressing) of each symptom in the past week. Using standard scoring for the DTS, subscale scores for each symptom cluster were calculated by summing the frequency and severity scores and a total score was created by summing the three subscale scores. Scores range from 0 to 40,0 to 56,0 to 50 , and 0 to 136 for intrusion, avoidance/numbing, hyper-arousal, and the total score, respectively.

The DTS provides a continuous measure of symptom severity and includes cut scores to develop diagnostic categories. Davidson (1996) suggests that a cut score of 40 may be used to identify individuals with a probable PTSD diagnosis since this cut score yields a positive predictive value of 0.92 , a negative predictive score of 0.79 , and a diagnostic accuracy of 0.83 . This scale has demonstrated strong reliability among rape victims, survivors of child abuse, and women exposed to IPV (Bradley et al. 2005; Davidson et al. 1997, 2002). Among these samples, Cronbach's alpha for the total scale has ranged from 0.79 to 0.99 indicating good to excellent internal consistency. In this study, Cronbach alpha's was .94, .94, .93, and .97 for the intrusion, avoidance/numbing, hyperarousal, and total score, respectively. In this study, 67 participants $(26.9 \%$ of those surveyed) did not complete the DTS as they responded negatively to the initial screening question. Thus, we present rates of exposure for the entire sample $(\mathrm{N}=247)$, but use only data from the sample that responded positively to the screening question $(n=171)$ to assess the relationship between categories of events and mothers' PTSD symptoms. 
Data Analysis

Data were analyzed using SPSS version 15.0 (SPSS Inc. 2006). Bivariate correlational analysis was used to address question 2, while One-way analysis of variance (ANOVA) with post-hoc test by Bonferroni was used to examine differences in mean intrusion, avoidance/numbing, and hyper-arousal symptoms among groups. Independent t-test of means was used to assess differences in means scores. Prior to the analyses, the data were assessed for the assumptions associated with the ANOVA including normal distribution and homogeneity of variance. The distribution for mothers' total PTSD, intrusion, avoidance/numbing, and hyperarousal scores were severely skewed and resembled an L-shape with zero. Transformation using the formula $1=\bullet x \cdot c \cdot$ did not significantly alter the skewness of the distribution, so the analysis proceeded without transformation. The assumption related to homogeneity of variance was satisfied. The significance level for all analyses was $\mathrm{p}<.05$.
Results

Lifetime Exposure to Adversity/Trauma and Rates of PTSD

Life-time frequency of exposure to 23 adversities and traumas is presented in Table 2. Almost $80 \%$ of mothers reported experiencing at least 1 of the 23 traumatic events in their life-time. Of the 11 adversities investigated, mothers experienced on average $2.44(S D=2.24)$ events over their lifetime. Approximately half of the sample reported one to two adversities, another quarter reported three to four adversities, and a much smaller proportion (4.8\%) reported 5 or more life-time adversities. In childhood, the most prominent adversities were being sent away/kicked out (24.9\%) and the unexpected death of some close (18.5\%). In adulthood, the most prominent adversities were the unexpected death of someone close (32.3\%) and witnessing a death or serious injury (18.5\%).

Almost $80 \%$ of the sample reported at least one lifetime psychological trauma. Of the four psychological traumas

Table 2 Lifetime Exposure to Adversities and Traumas

\begin{tabular}{|c|c|c|c|c|c|c|c|}
\hline \multirow{2}{*}{ Event type } & \multirow[t]{2}{*}{ Lifetime n(\%) } & \multicolumn{3}{|c|}{ \# of Childhood events $n(\%)$} & \multicolumn{3}{|c|}{ \# of Adulthood events n(\%) } \\
\hline & & $1-2$ & $3-4$ & $\cdot 5$ & $1-2$ & $3-4$ & $\cdot 5$ \\
\hline Became a refugee & $30(12.0)$ & $5(2.0)$ & - & - & $24(9.6)$ & $1(.4)$ & - \\
\hline Civilian persecution & $27(10.8)$ & $12(4.9)$ & $1(.4)$ & $5(2.0)$ & $11(4.5)$ & $2(.8)$ & $4(1.6)$ \\
\hline Auto accident & $26(10.4)$ & $13(5.2)$ & $1(.4)$ & - & $16(6.4)$ & $1(.4)$ & - \\
\hline Other accident & $17(6.8)$ & $7(2.8)$ & $1(.4)$ & - & $8(3.2)$ & $1(.4)$ & $3(1.2)$ \\
\hline Serious illness (self) & $28(11.2)$ & $5(2.0)$ & $1(.4)$ & - & $19(7.6)$ & $1(.4)$ & - \\
\hline Serious illness (child) & $24(9.6)$ & $1(.4)$ & - & - & 19(7.7) & - & $2(.8)$ \\
\hline Death/Apprehension (child) & $23(9.2)$ & $5(2.0)$ & - & - & $16(6.4)$ & $1(.4)$ & $1(.4)$ \\
\hline Witnessed death/injury & $75(30.1)$ & $34(13.8)$ & $3(1.2)$ & $6(2.4)$ & $37(14.9)$ & $3(1.2)$ & $6(2.4)$ \\
\hline Unexpected death & $120(48.2)$ & $58(23.4)$ & $4(1.6)$ & $3(1.2)$ & $64(25.7)$ & $6(2.4)$ & $10(4.0)$ \\
\hline Orphaned & $33(13.3)$ & $24(9.6)$ & $6(2.4)$ & $3(1.2)$ & - & - & - \\
\hline Sent away/kicked out & $69(27.7)$ & $44(17.7)$ & $1(1.6)$ & $15(6.0)$ & - & - & - \\
\hline Psychological trauma & & $1-2$ & $3-4$ & $\cdot 5$ & $1-2$ & $3-4$ & $\cdot 5$ \\
\hline Childhood emotional abuse & $97(39.0)$ & $3(1.2)$ & $2(.8)$ & $87(34.9)$ & - & - & - \\
\hline Witnessed IPV as a child & $96(38.6)$ & $22(9.0)$ & $9(3.7)$ & $57(23.4)$ & - & - & - \\
\hline IPV-psychological & $153(61.4)$ & $7(3.3)$ & $1(.5)$ & $26(12.1)$ & $30(12.7)$ & $3(1.3)$ & $103(43.6)$ \\
\hline Stalked & $81(32.5)$ & $15(6.2)$ & $2(.8)$ & $5(2.1)$ & $39(16.0)$ & $5(2.1)$ & $21(8.6)$ \\
\hline \multicolumn{8}{|l|}{ Assaultive trauma } \\
\hline Childhood Physical Abuse & $84(34.1)$ & $6(2.4)$ & $3(1.2)$ & $74(29.7)$ & - & - & - \\
\hline Childhood sexual abuse & $83(33.3)$ & $26(10.7)$ & $10(4.1)$ & $43(17.8)$ & - & - & - \\
\hline IPV physical & $133(53.4)$ & $14(5.8)$ & $3(1.2)$ & $17(7.0)$ & $36(14.9)$ & $12(5.0)$ & $70(28.9)$ \\
\hline IPV sexual & $67(26.9)$ & $11(4.4)$ & $2(.8)$ & $7(2.9)$ & $21(8.6)$ & $5(2.0)$ & 29(11.9) \\
\hline Rape & $85(34.1)$ & $38(15.4)$ & $4(1.6)$ & $16(6.5)$ & $26(10.6)$ & $3(1.2)$ & $12(4.9)$ \\
\hline Assault_physical (non-intimate) & $34(13.7)$ & $10(4.0)$ & $2(.8)$ & $3(1.2)$ & $15(6.0)$ & $2(.8)$ & $8(3.2)$ \\
\hline Assault-sexual (non-intimate) & $43(17.3)$ & $16(6.6)$ & $2(.8)$ & $9(3.7)$ & $13(5.3)$ & $1(.4)$ & $5(2.1)$ \\
\hline Kidnapped/Held captive & $22(8.8)$ & $5(2.0)$ & - & - & $13(5.2)$ & $2(.8)$ & $4(1.6)$ \\
\hline
\end{tabular}

${ }^{a}$ Lifetime totals may not equal childhood and adulthood totals if women experienced an event in both life stages. Childhood $=<18$ years old, Adulthood $=\cdot 18$ years old 
investigated, mothers experienced on average $1.82(\mathrm{SD}=$ 1.41) unique events over their lifetime. In childhood, the most prominent psychological traumas were Childhood Emotional Abuse (CEA: $38.0 \%$ ) and witnessing IPV (36.1\%). In adulthood, psychological IPV was reported by $57.6 \%$ of the sample, while $26.7 \%$ reported being stalked at least once during adulthood. Unlike adversities, which tended to occur one to two times, the pattern of psychological trauma was more chronic and enduring. Of the 92 mothers who reported CEA, 94.5\% reported experiencing this 5 or more times compared to $3.2 \%$ who reported only one to two experiences. Similarly, of the 136 mothers who reported adulthood psychological IPV, 75.7\% reported experiencing this 5 or more times compared to $22.1 \%$ who reported they experienced this type of trauma only one or two times.

Seventy-eight percent of the sample reported at least one life-time assaultive trauma. Of the eight assaultive traumas investigated, mothers experienced on average 2.18 (SD = 1.79) unique events over their lifetime. In childhood, the most frequently reported assaultive traumas were CPA (33.3\%), childhood sexual abuse (CSA: $32.6 \%$ ), and rape (23.5\%). During adulthood, the most prominent events were physical IPV (48.8\%), sexual IPV (22.5\%), and being kidnapped/held captive (17.6\%). Across developmental stages, rape and being kidnapped/held captive were reported predominately as single events, while child abuse and IPV-related events seem to reflect a more chronic and enduring pattern. Of the 58 and $\mathbf{4 1}$ mothers who reported rape in childhood and adulthood respectively, $65.5 \%$ and $63.4 \%$ reported that these events occurred once or twice. However, among the 83 and 118 mothers who reported CPA and physical IPV respectively, $89.2 \%$ and $59.3 \%$ reported experiencing these events five times or greater.

To determine the prevalence of PTSD in this sample, symptom ratings on the Davidson Trauma Scale were used. As suggested by Davidson (1996), a cut score of 40 was used to identify individuals with a probable PTSD diagnosis. When this criterion was used, 75 women (31\%) had symptoms consistent with a probable diagnosis of PTSD.

Associations Between Lifetime Exposure to Multiple Adversities and Traumas and PTSD Symptoms

Table 3 presents the zero order correlations, mean, standard deviations and range for the study variables. Lifetime exposure to multiple adversities not associated with mother's current avoidance/numbing $(r=.128, p=.047)$, hyper-arousal $(r=.064, p=.203)$, or total PTSD symptoms $(r=.129, p=.046)$. However it was weakly and positively associated with mothers' current intrusion/re-experiencing symptoms $(r=.139, p=.035)$. Lifetime exposure to multiple psychological traumas was moderately associated with mother current avoidance/numbing $(r=.434, p<.001)$, hyper-arousal $(r=.332, p<.001)$, and total PTSD symptom $(r=.395, p=.001)$. However it was weakly and positively associated with mothers' current intrusion/re-experiencing symptoms $(r=.245, p=.001)$. Lifetime exposure to multiple assaultive traumas was weakly associated with mother current intrusive/re-experiencing $(r=.141, p=.033)$, avoidance/numbing $(r=.277, p<.001)$, hyper-arousal $(r=.246$, $\mathrm{p}=.001)$, and total PTSD symptom $(\mathrm{r}=.266, \mathrm{p}<.001)$. Thus, the findings reveal that for the most part, lifetime exposure to adversities is not associated with mothers' current PTSD symptomology. Both psychological and assaultive trauma exposure are associated with mothers' current PTSD symptoms, however, the psychological category of events appears to have a stronger association than assaultive trauma.

Differences in PTSD Symptomology Across Levels of Exposure to Adversities and Trauma

Results of the one-way ANOVA of mean intrusion, avoidance/numbing, and hyperarousal scores for each
Table 3 Zero order correlations, means, and standard deviations, for study variables $(n=171)$

\footnotetext{
${ }^{a}$ Lifetime exposure to multiple unique events

${ }^{*} \mathrm{p}<.05,{ }^{*} \mathrm{p}<.01$ (1-tailed)
}

\begin{tabular}{llllllll}
\hline & 1 & 2 & 3 & 4 & 5 & 6 & 7 \\
\hline Adversity $^{\mathrm{a}}$ & - & & & & & & \\
Psychological $^{\mathrm{a}}$ & $.246^{* *}$ & - & & & & & \\
Assaultive $^{\mathrm{a}}$ & $.252^{* *}$ & $.543^{* *}$ & - & & & & \\
Intrusion/Re-experiencing $^{* *}$ & $.139^{*}$ & $.245^{* *}$ & $.141^{*}$ & - & & & \\
Avoidance/Numbing & .128 & $.434^{* *}$ & $.277^{* *}$ & $.633^{* *}$ & - & & \\
Hyper-arousal & .064 & $.332^{* *}$ & $.246^{* *}$ & $.538^{* *}$ & $.710^{* *}$ & - & \\
Total PTSD & .129 & $.395^{* *}$ & $.266^{* *}$ & $.820^{* *}$ & $.913^{* *}$ & $.864^{* *}$ & - \\
Descriptive & & & & & & & \\
Mean & 2.50 & 3.09 & 3.46 & 10.39 & 14.75 & 14.26 & 39.58 \\
SD & 1.89 & 2.13 & 2.53 & 10.82 & 13.52 & 13.52 & 31.44 \\
Min, Max & 0,9 & 0,9 & 0,12 & 0,40 & 0,56 & 0,56 & 0,134 \\
\hline
\end{tabular}


grouping of adversity and trauma are presented in Table 4. For this analysis, exposure scores were divided into three exposure grouping such that group 1 represented 0 lifetime exposure to any adversity or trauma, group 2 represented exposure to 1 or 2 unique lifetime events, while group 3 represented exposure to 3 or more unique lifetime events. Several observations can be made. First, with respect to adversity, level of exposure to this category of events does not differentiate mean symptoms scores. That is, the patterning of PTSD symptoms does not appear to be influenced by the number of unique adverse events to which mothers are exposed over their lifetime with mean scores for intrusion, avoidance/numbing, and hyperarousal remaining equal across exposure groupings. Second, psychological trauma is the only trauma type that differentiates mean scores across all symptom clusters. Importantly, there appears to be a positive association between level of exposure to psychological trauma and symptom severity. Across all symptom clusters, mothers reporting 3 or more unique psychological encounters reported more severe symptoms that those who experienced one to two events. This group in turn reported more severe symptoms than those reporting no lifetime exposure to psychological trauma. Third, although levels of exposure to assaultive trauma was expected to differentiate mean symptom scores across all PTSD symptom clusters, our initial analysis revealed that it differentiated only mean avoidance/numbing and hyper-arousal scores. For the avoidance/numbing cluster of symptoms, assaultive trauma exposure appears to have a similar pattern as psychological trauma exposure whereby a clear positive association is demonstrated. For intrusive and hyperarousal symptoms, a pattern was less pronounced, however mothers reporting 3 or more assaultive events tended to experience most severe symptoms.

\section{Discussion}

This study contributes to the literature by providing a comprehensive assessment of both the type and timing of adversities and trauma experienced by an urban sample of income-assisted single mothers and contributes some insights into the relative importance of adversities, psychological traumas, and assaultive traumas exposure to the development and persistence of PTSD symptoms.

\section{Adversities, Trauma, and PTSD Symptom Levels}

Participants in this study experienced a wide range of adverse and traumatic events, with approximately $80 \%$ reporting at least 1 lifetime adversity, psychological trauma, and assaultive trauma. This finding of widespread exposure is consistent with other general population surveys that assessed a similar range of adversities and traumas among women (Breslau et al. 1998; Davies et al. 1997; Kessler et al. 1995; Stein et al. 1997).

Thirty-one percent of the sample had PTSD symptom levels consistent with a probable diagnosis of PTSD. This rates is significantly higher than the $3.0 \%$ to $10.0 \%$ and $2.5 \%$ to $5.0 \%$ prevalence rate found among the general female and male population, respectively (Breslau et al. 1998 ), but consistent with the prevalence rate of $29.5 \%$

Table 4 Differences in mean intrusion, avoidance/numbing, and hyperarousal scores by multiple exposure grouping $(n=171)$

\begin{tabular}{|c|c|c|c|c|c|c|c|c|c|c|c|c|c|}
\hline \multirow{2}{*}{$\begin{array}{l}\text { Groups-No. of unique } \\
\text { events }\end{array}$} & & \multicolumn{3}{|c|}{ Intrusion } & \multirow{2}{*}{$\begin{array}{l}\text { ANOVA } \\
\mathrm{F}\end{array}$} & \multicolumn{3}{|c|}{ Avoidance/Numbing } & \multirow{2}{*}{$\begin{array}{l}\text { ANOVA } \\
\text { F }\end{array}$} & \multicolumn{3}{|c|}{ Hyperarousal } & \multirow{2}{*}{$\begin{array}{l}\text { ANOVA } \\
\text { F }\end{array}$} \\
\hline & & $\mathrm{n}$ & $x$ & SD & & $\mathrm{n}$ & $x$ & SD & & $n$ & $x$ & SD & \\
\hline \multirow[t]{2}{*}{ Adversity $^{\mathbf{a}}$} & $\begin{array}{l}1 \\
2\end{array}$ & $\begin{array}{l}28 \\
65\end{array}$ & $\begin{array}{r}9.32 \\
11.23\end{array}$ & $\begin{array}{r}10.21 \\
9.89\end{array}$ & \multirow[t]{2}{*}{$.366 \mathrm{~ns}$} & $\begin{array}{l}28 \\
65\end{array}$ & $\begin{array}{l}15.68 \\
13.78\end{array}$ & $\begin{array}{l}11.80 \\
13.76\end{array}$ & \multirow[t]{2}{*}{$.276 \mathrm{~ns}$} & $\begin{array}{l}28 \\
65\end{array}$ & $\begin{array}{l}14.00 \\
14.81\end{array}$ & $\begin{array}{l}12.10 \\
11.10\end{array}$ & \multirow[t]{2}{*}{$.120 \mathrm{~ns}$} \\
\hline & 3 & 78 & 10.06 & 11.81 & & 78 & 15.22 & 13.99 & & 78 & 13.88 & 12.03 & \\
\hline T-test of means & & \multicolumn{3}{|c|}{$X_{g r p ~ 1}=X_{g r p 2}=X_{g r p ~ 3}$} & & \multicolumn{3}{|c|}{$X_{\text {grp } 1}=X_{\operatorname{grp~2}}=X_{\operatorname{grp~} 3}$} & & \multicolumn{3}{|c|}{ 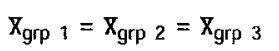 } & \\
\hline \multirow[t]{2}{*}{ Psychological Trauma ${ }^{a}$} & $\begin{array}{l}1 \\
2\end{array}$ & $\begin{array}{l}15 \\
63\end{array}$ & $\begin{array}{l}3.60 \\
8.89\end{array}$ & $\begin{array}{r}4.98 \\
10.29\end{array}$ & \multirow[t]{3}{*}{$5.61 * *$} & $\begin{array}{l}15 \\
63\end{array}$ & $\begin{array}{r}1.60 \\
11.87\end{array}$ & $\begin{array}{r}2.55 \\
11.78\end{array}$ & \multirow[t]{2}{*}{$14.81^{* * *}$} & $\begin{array}{l}15 \\
63\end{array}$ & $\begin{array}{r}4.07 \\
12.17\end{array}$ & $\begin{array}{r}3.73 \\
10.68\end{array}$ & \multirow[t]{2}{*}{$11.16^{* * *}$} \\
\hline & 3 & 93 & 12.49 & 11.30 & & 93 & 18.82 & 13.88 & & 93 & 17.31 & 11.91 & \\
\hline T-test of means & & \multicolumn{3}{|c|}{$X_{\text {grp } 1}>X_{\text {grp } 2}>X_{\text {grp } 3}$} & & \multicolumn{3}{|c|}{$X_{\operatorname{grp~} 1}>X_{\operatorname{grp~} 2}>X_{\operatorname{grp~} 3}$} & & \multicolumn{3}{|c|}{ 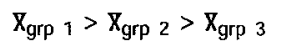 } & \\
\hline \multirow[t]{2}{*}{ Assaultive Trauma ${ }^{a}$} & $\begin{array}{l}1 \\
2\end{array}$ & $\begin{array}{l}11 \\
60\end{array}$ & $\begin{array}{r}4.73 \\
10.05\end{array}$ & $\begin{array}{r}6.96 \\
10.63\end{array}$ & \multirow[t]{2}{*}{$1.84 \mathrm{~ns}$} & $\begin{array}{l}11 \\
60\end{array}$ & $\begin{array}{r}8.00 \\
11.92\end{array}$ & $\begin{array}{l}13.47 \\
11.22\end{array}$ & \multirow[t]{2}{*}{$4.50 *$} & $\begin{array}{l}11 \\
60\end{array}$ & $\begin{array}{l}11.18 \\
11.72\end{array}$ & $\begin{array}{l}12.36 \\
10.72\end{array}$ & \multirow[t]{2}{*}{$3.18^{*}$} \\
\hline & 3 & 100 & 11.21 & 11.15 & & 100 & 17.19 & 14.30 & & 100 & 16.12 & 11.84 & \\
\hline T-test of means & & \multicolumn{4}{|c|}{$\begin{array}{c}X_{\text {grp } 2}=X_{\text {grp } 1}, X_{\text {grp } 2}= \\
X_{\text {grp 3, }}, X_{\text {grp 3 }}>X_{\text {grp } 1}\end{array}$} & \multicolumn{4}{|c|}{$\mathrm{X}_{\mathrm{grp} 1}>\mathrm{X}_{\mathrm{grp} 2}>\mathrm{X}_{\mathrm{grp} 3}$} & \multicolumn{3}{|c|}{$\begin{array}{c}X_{\text {grp } 1}=X_{\text {grp 2 }}, X_{\text {grp } 3}= \\
X_{\text {grp } 1,}, X_{\text {grp } 3}>X_{\text {grp } 2}\end{array}$} & \\
\hline
\end{tabular}

${ }^{a}$ For adversity, psychological trauma and assaultive trauma grp $1=0$ lifetime exposure, grp $2=1-2$ unique lifetime events, grp $3=\cdot 3$ unique lifetime events

${ }^{*} \mathrm{p}<.05,{ }^{* *} \mathrm{p}<.01,{ }^{* * *} \mathrm{p}<.001$ 
found in a random sample of single mothers receiving social assistance in the United States (Tolman and Rosen 2001). Compared to one other Canadian study (Afifi et al. 2006) which found that $8.4 \%, 16.6 \%$, and $22.9 \%$ of married, never-married and separated/divorced single mothers, respectively, experienced life-time PTSD, the findings of this study revealed that $24.8 \%$ of single never married and $41.7 \%$ of separated and/or divorced single mothers receiving social assistance reported symptom levels consistent with probable PTSD. In addition to addressing how PTSD varies by prior family structure, these results may also speak to women's exposure to psychological and assaultive violence prior to separation and/or divorce.

Relationship Between Adversities, Trauma and PTSD Symptom Severity

Although we anticipated that adversity exposure would contribute significantly to the severity of and patterning of PTSD symptom, our findings did not support this position. Adversity exposure was weakly associated with only with mothers' intrusive or re-experiencing symptom levels. Furthermore, levels of exposure did not differentially affect mean scores for re-experiencing, avoidance/ numbing, or hyperarousal symptoms. At least for this sample, it appears after all, that the precipitating event does indeed need to reach the level of severity and intensity implied by the DSM-IV-TR (American Psychiatric Association 2000) in order to cause substantial levels of PTSD symptoms.

Our analysis suggests that both exposure to psychological and assaultive traumas and the number of unique events mothers experience are positively associated with PTSD symptom severity. Although psychological traumas have traditionally been excluded from the category of events that may precipitate PTSD, the findings of this study suggest that psychological violence/abuse perpetrated by parents/guardians and partners is more strongly associated with PTSD symptom severity than assaultive trauma. Our analysis builds upon the work of (Breslau et al. 1999), who demonstrated that women's greater risk for PTSD when compared to males could be attributed to a vulnerability to assaultive trauma. Our findings suggest that women may also have a vulnerability to psychological violence.

Recent intimate partner violence research supports our findings and further suggested that it is the psychological, not the assaultive component of intimate partner violence, that is the stronger predictor of posttraumatic stress disorder (Coker et al. 2000; Pico-Alfonso 2005; Smith et al. 2002). The findings relevant to the patterning of symptoms are remarkable. Levels of exposure to psychological trauma differentially impacted mean symptom scores with the severity of symptoms increasing as the number of unique events encountered over women's lifetime also increased. On the contrary, level of exposure to assaultive trauma appears to have it greatest differential impact on the severity of women avoidance/numbing scores. Further research is needed to determine how the patterning of symptoms by event type influences the recovery process and participation in the usual activities of daily living. We suspect that psychological violence may have a more debilitating effect and a natural but significant impact on women's workforce participation.

Our findings implicitly address the issue of childhoodadulthood revictimization and more explicitly the issue of prior exposure and their potential impact on mental wellbeing. The findings suggest that prior exposure matters to the patterning of PTSD symptoms. Repeated exposure to assaultive trauma is more likely to elevate mothers' avoidance symptoms while, repeated exposure to psychological trauma is likely to elevate all PTSD symptoms. Furthermore, it appears that exposure to one or both will have significant implications for women's capacity to engage with their physical and social world, as well as their capacity to engage with health and social service providers.

It should be noted that rates of CEA and being stalked found in this study were eight times that found in the general female population (Mullen et al. 1996; Tjaden and Thoennes 2000), while psychological IPV was 4.5 times that of the general female population (Coker et al. 2005; Smith et al. 2002). Almost $39.0 \%$ of our sample reported witnessing IPV, a similar rate to that reported by homeless and income-assisted single mothers in the United States (Bassuk et al. 2006), but almost six times that found among the general female population (Bensley et al. 2003). Not only did this sample of single mothers report greater rates of lifetime exposure to psychological trauma, the patterning of exposure was similar to assaultive trauma but significantly different from the patterning of adversity exposure. Mothers tended to experience adversities as isolated events while psychological and assaultive traumas were more chronic and enduring. This enduring and chronic pattern may in part explain the high symptoms levels observed here as well as the differential impact on each on each cluster of PTSD symptoms.

Several interpretations are possible in explaining both the levels of exposure reported here and the dominant contributory effect of psychological trauma on PTSD symptom levels. First, it is possible that the findings reflect a social selection process whereby childhood exposure to psychological trauma alters a number of other life trajectories including education, employment, and subsequent exposure to adolescent and adulthood trauma, and early on-set mental illness (Brush 2000; Jayakodya et al. 1998). These intersecting experiences may cause significant 
relational, mental, and functional problems that lead women to seek income assistance.

Second, recall bias may have influenced the data quality about frequency of exposure and, thus, artificially inflated the potential effect of psychological trauma on mothers PTSD symptom levels. Widom et al. (2004) suggest that recall bias or patterns of accuracy and inaccuracy in reporting prior experiences differ across groups of varying physical and mental health status. Thus, compared to people with better current mental health, people with poor current mental health may be more likely to remember earlier negative life experiences, interpret earlier events as more severe and/or abusive in nature, and over-report the frequency with which those events occurred. Recall bias is of particular relevance here as the high PTSD symptom levels found among this sample increases the potential for over-reporting trauma experiences.

Also of concern are measurement issues that may arise from the overlap in women's experiences, particularly as they related to frequency of exposure to psychological and assaultive traumas. Twenty-three mothers reported exposure only to adversities, while four mothers reported exposure only to psychological or assaultive traumas. Exposure to psychological and assaultive traumas rarely occurred in isolation as evidenced by the strong bi-variate correlations $(r=.59)$. Furthermore, in this sample, 144 of the 247 mothers reported exposure to all three types of events. While the results presented here may be influenced by the overlap in women's experiences, they also brings to light the conceptual and analytical problems researchers face in attempting to disentangle the impact of events that are so closely linked. This perhaps suggests that the recent move toward examining the cumulative effects of traumas and adversities is a more appropriate and progressive approach to trauma and mental health research.

Finally, given that the potential effects of psychological trauma are only now being investigated in relation to PTSD and psychological and assaultive traumas were highly correlated $(r=.54)$, it is possible the positioning of assaultive trauma as the primary cause of PTSD in prior research is partially due to the failure to consider psychological traumas in the same analysis. Both the finding that assaultive trauma is associated with mothers' PTSD symptoms and is relatively less important than psychological traumas is supported by previous literature (Coker et al. 2000; Pico-Alfonso 2005).

\section{Limitations and Implications}

This is a cross-sectional study with a sample drawn only from one city in Canada. Although representative of single mothers on social assistance in the city where the study was completed, the findings may not be generalizable particu- larly when considering regional differences in population demographics. Although attempts were made to recruit a random sample, the low response rate also makes generalization problematic.

Methodologically, the cross-sectional design limits the ability to make causal inferences about the relationship between adversities, traumas and PTSD symptoms. Furthermore, cross-sectional designs are problematic in that spurious relationships between variables may be interpreted as genuine relationships (Tabachnick and Fidell 2001). It is recognized that longitudinal data would be more appropriate in examining the relationships between the variables outlined in the model. However, given that this is an unexplored area of research, the cross-sectional designed is justified.

Finally, women belonging to South Asian and Middle Eastern cultures frequently refused to answer the questions related to psychological and assaultive traumas stating 'in our culture we don't discuss those things'. This too might create a bias whereby the prevalence of exposure to psychological and assaultive traumas is underestimated.

At a conceptual level, Herman (1997) has argued that the symptom clusters identified by the American psychiatric Association-persistent re-experiencing of the traumatic event, avoidance of stimuli associated with the trauma and numbing of general responsiveness, and heightened arousaldo not adequately capture the psychological response that occurs with prolonged, repeated trauma. Herman's work attends primarily to the effects of assaultive and psychological trauma and suggests that complex PTSD may be the best way to categorize the symptoms of patients who have suffered prolonged trauma. Thus, our use of the DTS limits our capacity to speak to the broad spectrum of PTSD related symptoms that women in this sample may have experienced.

Even in light of these limitations, results of this study have significant implications for mental health promotion across health and social service sectors. The higher levels of assaultive and psychological traumas found in this study suggest the need for a gender-sensitive approach to violence prevention. Public health practitioners have a role to play in developing violence prevention strategies that deter the perpetration of violence against women across all developmental stages. Public health nurses may use a number of health promotion strategies to target violence prevention among the most vulnerable populations in society.

The demonstrated relationships between adversities and traumas and current PTSD symptom levels suggest that mental health professionals and social service providers should routinely assess for exposure, and psychological responses to these events, including the full range of depressive, anxiety, and substance abuse disorders, and initiate appropriate clinical support and referral to manage these problems when necessary. The effects of assaultive and 
psychological traumas are enduring and must be addressed both within the context of violence prevention and connecting women with mental health professionals who can provide specialized mental health services to this population.

Women may need income assistance, in part, because of the debilitating effects of trauma. Social service programs have a role to play in proactively linking women with appropriate services to address their mental health concerns. This is an essential component to helping women re-enter the work force. Bryne et al. (1998) demonstrated the effectiveness of using public health nurses to provide inhomes services to single mothers on social assistance. Nurses may play an important role in connecting women to needed resources such as specialized mental health care or in the case of advanced practice nurses, providing treatment themselves.

The nurse and other mental health practitioners have a role to play in assessing for comorbid mental health problems. The mean score for the Davidson Trauma Scale of 29.15 indicates relatively high PTSD symptom levels for this group of single mothers, suggesting that some single mothers exposed to traumas may have been experiencing distress and/or impairment in functioning without the full range of PTSD symptoms. Further, because PTSD symptoms overlap with depressive symptoms and complex PTSD, to some extent, the high scores may be indicative of other comorbid mental health problems not measured in this study. These findings may suggest the need to assess trauma exposure and various psychological responses to trauma including the symptom PTSD symptom clusters are most impact for the individual.

\section{Conclusion}

This study was completed with the goal of creating knowledge that may be used to promote the mental health of single mothers. To this end, our assessment of mothers' trauma histories suggests that upstream and downstream health promotion initiatives must focus on reducing women and children's exposure to trauma, particularly psychological violence. Additionally, there is a need to appropriately assess income-assisted single mothers' current mental health and intervene by promoting access to health and social resources that may promote mental well-being.

\section{References}

Afifi, T. O., Cox, B. J., \& Enns, M. W. (2006). Mental health profiles among married, never-married, and separated/divorced mothers in a nationally representative sample. Social Psychiatry and Psychiatric Epidemiology, 41(2), 122-129.
American Psychiatric Association. (2000). 309.81 posttraumatic stress disorder. In Author (Ed.), Diagnostic and statistical manual of mental disorders (IV-TR ed., pp. 424-429). Washington, DC: American Psychiatric Association.

Avison, W. R., Ali, J., \& Walters, D. (2007). Family structure, stress, and psychological distress: a demonstration of the impact of differential exposure. Journal of Health and Social Behavior, 48 (3), 301.

Bassuk, E. L., Buckner, J. C., Perloff, J. N., \& Bassuk, S. S. (1998). Prevalence of mental health and substance use disorders among homeless and low-income housed mothers. The American Journal of Psychiatry, 155(11), 1561-1564.

Bassuk, E. L., Dawson, R., \& Huntington, N. (2006). Intimate partner violence in extremely poor women: longitudinal patterns and risk markers. Journal of Family Violence, 21, 387-399.

Bensley, L., Van Eenwyk, J., \& Wynkoop Simmons, K. (2003). Childhood family violence history and women's risk for intimate partner violence and poor health. American Journal of Preventive Medicine, 25(1), 38-44.

Bradley, R., Schwartz, A. C., \& Kaslow, N. J. (2005). Posttraumatic stress disorder symptoms among low-income, African American women with a history of intimate partner violence and suicidal behaviors: self-esteem, social support, and religious coping. Journal of Traumatic Stress, 18(6), 685-696.

Breslau, N., Kessler, R. C., Chilcoat, H. D., Schultz, L. R., Davis, G. C., \& Andreski, P. (1998). Trauma and posttraumatic stress disorder in the community: the 1996 detroit area survey of trauma. Archives of General Psychiatry, 55(7), 626-632.

Breslau, N., Chilcoat, H. D., Kessler, R. C., Peterson, E. L., \& Lucia, V. C. (1999). Vulnerability to assaultive violence: further specification of the sex difference in post-traumatic stress disorder. Psychological Medicine, 29(4), 813-821.

Brown, G. W., \& Moran, P. M. (1997). Single mothers, poverty and depression. Psychological Medicine, 27, 21-33.

Brush, L. D. (2000). Battering, traumatic stress, and welfare-to-work transition. Violence Against Women, 6(10), 1039-1065.

Bryne, C., Brown, G., Roberts, J., Ewart, B., Schuster, M., \& Underwood, J. (1998). Surviving social assistance: 12 month prevalence of depression in sole-support parents receiving social assistance. Canadian Medical Association, 158(7), 881-888.

Coker, A. L., Smith, P. H., Bethea, L., King, M. R., \& McKeown, R. $E$. (2000). Physical health consequences of physical and psychological intimate partner violence. Archives of Family Medicine, 9(5), 451-457.

Coker, A. L., Smith, P. H., Thompson, M. P., Mckeown, R. E., Bethea, L., \& Davis, K. E. (2002). Social support protects against the negative effects of partner violence on mental health. Journal of Women's Health \& Gender-Based Medicine, 11(5), 465-476.

Coker, A. L., Weston, R., Creson, D. L., Justice, B., \& Blakeney, P. (2005). PTSD symptoms among men and women survivors of intimate partner violence: the role of risk and protective factors. Violence and Victims, 20(6), 625-643.

Davidson, J. R. T. (1996). Davidson trauma scale (DTS). North Tonawanda: Multi-Health Systems Inc.

Davidson, J. R., Book, S. W., Colket, J. T., Tupler, L. A., Roth, S., David, D., et al. (1997). Assessment of a new self-rating scale for posttraumatic stress disorder. Psychological Medicine, 27(1), 153-160.

Davidson, J. R., Tharwani, H. M., \& Connor, K. M. (2002). Davidson trauma scale (DTS): normative scores in the general population and effect sizes in placebo-controlled SSRI trials. Depression and Anxiety, 15(2), 75-78.

Davies, L., Avison, W. R., \& McAlpine, D. D. (1997). Significant life experiences and depression among single and married mothers. Journal of Marriage and the Family, 59(2), 294-308.

Dillman, D. A. (1991). The design and administration of mail surveys. Annual Reviews Sociology, 17, 225-249. 
Goldberg, L. R, \& Freyd, J. J. (2006). Self-reports of potentially traumatic experiences in an adult community sample: Gender differences and test-retest stabilities of the items in a brief betrayal-trauma survey. Journal of Trauma and Dissociation, 7 (3), 39-63.

Goodman, L., Saxe, L., \& Harvey, M. (1991). Homelessness as psychological trauma. Broadening perspectives. The American Psychologist, 46(11), 1219-1225.

Goodman, L., Dutton, M. A., Weinfurt, K., \& Cook, S. (2003). The intimate partner violence strategies index: development and application. Violence Against Women, 9(2), 163.

Herman, J. L. (1997). Trauma and recovery: The aftermath of violence -from domestic abuse to political terror (Revised ed.). New York: Basic Books.

Jayakodya, R., Danzigerb, S., \& Kessler, R. C. (1998). Early-onset psychiatric disorders and male socioeconomic status. Social Science Research, 27(371).

Kessler, R. C., Sonnega, A., Bromet, E., Hughes, M., \& Nelson, C. B. (1995). Posttraumatic stress disorder in the national comorbidity survey. Archives of General Psychiatry, 52(12), 1048-1060.

Lloyd, D. A., \& Turner, R. J. (2003). Cumulative adversity and posttraumatic stress disorder: evidence from a diverse community sample of young adults. The American Journal of Orthopsychiatry, 73(4), 381-391.

Lown, E. A., Schmidt, L. A., \& Wiley, J. (2006). Interpersonal violence among women seeking welfare: unraveling lives. American Journal of Public Health, 96(8), 1409-1415.

Lutenbacher, M. (2000). Perceptions of health status and the relationship with abuse history and mental health in lowincome single mothers. Journal of Family Nursing, 6(4), 320340 .

Mullen, P. E., Martin, J. L., Anderson, J. C., Romans, S. E., \& Herbison, G. P. (1996). The long-term impact of the physical, emotional, and sexual abuse of children: a community study. Child Abuse \& Neglect, 20(1), 7-21.

Ontario Ministry of Community and Social Services. (2010). Social assistance in ontario: Monthly statistical reports. Retrieved 06/ 21, 2010, from http://www.mcss.gov.on.ca/en/mcss/programs/ social/reports/index.aspx.

Pico-Alfonso, M. A. (2005). Psychological intimate partner violence: the major predictor of posttraumatic stress disorder in abused women. Neuroscience and Biobehavioral Reviews, 29(1), 181193.

Salomon, A., Bassuk, E. L., Browne, A., Bassuk, S. S., Dawson, R., \& Huntington, N. (2004). Secondary data analysis on the etiology, course, and consequences of intimate partner violence against extremely poor women No. NCJ 199714). Rockville: National Criminal Justice Reference Service.

Samuels-Dennis, J., Ford-Gilboe, M., Avison, W., Wilk, P., \& Ray, S. (2010a). Cumulative trauma, personal and social resources, and post-traumatic stress disorder single mothers receiving social assistance. Journal of Family Violence, 26(6), 603-617.

Samuels-Dennis, J., Ford-Gilboe, M., \& Bailey, A. (2010b). The intersectionality model of trauma and post-traumatic stress disorder (IMT-PTSD). In O. Havinsky (Ed.), Intersectionalitytype health research in Canada (Forthcoming). Vancouver: UBC.

Schumm, J. A., Briggs-Phillips, M., \& Hobfoll, S. E. (2006). Cumulative interpersonal traumas and social support as risk and resiliency factors in predicting PTSD and depression among inner-city women. Journal of Traumatic Stress, 19(6), 825-836.

Smith, P. H., Thornton, G. E., DeVellis, R., Earp, J., \& Coker, A. L. (2002). A population-based study of the prevalence and distinctiveness of battering, physical assault, and sexual assault in intimate relationships. Violence Against Woman, 8(10), 12081232.

SPSS Inc. (2006). SPSS for windows. Chicago, IL.

Stein, M. B., Walker, J. R., Hazen, A. L., \& Forde, D. R. (1997). Full and partial posttraumatic stress disorder: findings from a community survey. The American Journal of Psychiatry, 154 (8), 1114-1119.

Tabachnick, B. G., \& Fidell, L. S. (2001). Using multivariate statistics (4th ed.). Needham Heights: Allyn \& Bacon, Inc.

Tjaden, P., \& Thoennes, N. (2000). Full report of the prevalence, incidence, and consequences of violence against women No. NCJ 183781. Washington: U.S. Department of Justice.

Tolman, R. M., \& Rosen, D. (2001). Domestic violence in the lives of women receiving welfare: mental health, substance dependence, and economic well-being. Violence Against Women, 7(2), 141158.

Toronto Community and Neighbourhood Services. (2004). Social assistance and social exclusion: Findings from Toronto social services' 2003 survey of single parents on Ontario works (Final Report. Toronto: Toronto Community and Neighbourhood Services.

Turner, R. J., \& Avison, W. R. (2003). Status variations in stress exposure: Implications for the interpretation of research on race, socioeconomic status, and gender. Journal of Health and Social Behavior, 44(4), 488-505.

Widom, C. S., Raphael, K. G., \& DuMont, K. A. (2004). The case for prospective longitudinal studies in child maltreatment research: commentary on Dube, Williamson, Thompson, Felitti, and Anda (2004). Child Abuse \& Neglect, 28(7), 715-722.

World Health Organization. (2004). The world health organization (WHO) world mental health (WMH) survey initiative version of the composite international diagnostic interview (CIDI). Retrieved August/20, 2009, from http://www.hcp.med.harvard. edu/wmhcidi/ftpdir_public/capi_instrument/capi_v20_pdf/ CAPI\%20V20\%20-\%20Post\%20Traumatic\%20stress\%20Disorder.pdf 